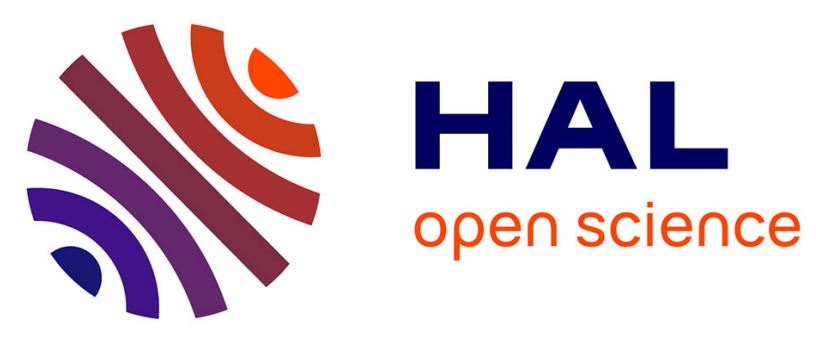

\title{
Co-ordinated observations of transient luminous events during the EuroSprite 2003 campaign
}

Torsten Neubert, Thomas Allin, Elisabeth Blanc, Thomas Farges, Christos Haldoupis, Agnes Mika, Serge Soula, Lars Knutsson, Oscar van Der Velde, Robert Marshall, et al.

\section{To cite this version:}

Torsten Neubert, Thomas Allin, Elisabeth Blanc, Thomas Farges, Christos Haldoupis, et al.. Coordinated observations of transient luminous events during the EuroSprite 2003 campaign. Journal of Atmospheric and Solar-Terrestrial Physics, 2005, 67 (8-9), pp.807-820. 10.1016/j.jastp.2005.02.004 . hal-00138811

\section{HAL Id: hal-00138811 https://hal.science/hal-00138811}

Submitted on 17 Sep 2021

HAL is a multi-disciplinary open access archive for the deposit and dissemination of scientific research documents, whether they are published or not. The documents may come from teaching and research institutions in France or abroad, or from public or private research centers.
L'archive ouverte pluridisciplinaire $\mathbf{H A L}$, est destinée au dépôt et à la diffusion de documents scientifiques de niveau recherche, publiés ou non, émanant des établissements d'enseignement et de recherche français ou étrangers, des laboratoires publics ou privés. 


\title{
Co-ordinated observations of transient luminous events during the EuroSprite2003 campaign
}

\author{
Torsten Neubert ${ }^{\mathrm{a}, *}$, Thomas H. Allin ${ }^{\mathrm{b}}$, Elisabeth Blanc ${ }^{\mathrm{c}}$, Thomas Farges ${ }^{\mathrm{c}}$, \\ Christos Haldoupis ${ }^{\mathrm{d}}$, Agnes Mika ${ }^{\mathrm{d}}$, Serge Soula ${ }^{\mathrm{e}}$, Lars Knutsson ${ }^{\mathrm{e}}$, \\ Oscar van der Velde ${ }^{\mathrm{e}}$, Robert A. Marshall ${ }^{\mathrm{f}}$, Umran Inan $^{\mathrm{f}}$, Gabriella Sátori ${ }^{\mathrm{g}}$, \\ Jozsef Bór $^{\mathrm{g}}$, Arthur Hughes ${ }^{\mathrm{h}}$, Andrew Collier ${ }^{\mathrm{h}}$, Steen Laursen ${ }^{\mathrm{a}}$, Ib L. Rasmussen ${ }^{\mathrm{a}}$ \\ ${ }^{a}$ Danish National Space Center, Juliane Maries Vej 30, Copenhagen 2100, Denmark \\ ${ }^{\mathrm{b}}$ Oersted-DTU, Danish Technical University, Kgs. Lyngby, Denmark \\ ${ }^{\mathrm{c}}$ Commissariat Energie Atomique, Bruyeres-le-Chatel, France \\ ${ }^{\mathrm{d}}$ Department of Physics, University of Crete, Heraklion, Greece \\ 'Laboratoire d'Aerologie, Universite Paul Sabatier, Toulouse, France \\ ${ }_{\mathrm{f}}^{\mathrm{f}}$ Space Telecommunications and Radio Science Laboratory, Stanford University, Stanford, USA \\ ${ }^{\mathrm{g}}$ Geodetic and Geophysical Research Institute, Sopron, Hungary \\ ${ }^{\mathrm{h}}$ Space Physics Research Institute, University of Natal, Durban, South Africa
}

During the Northern Hemisphere summer of 2003 a sprite observation campaign was conducted from Southern Europe and the magnetically conjugate region in South Africa. The campaign brought together a wide variety of instrumentation to investigate the effects of sprites on the mesosphere, and to search for signatures of the relativistic electron acceleration process in the magnetically conjugate hemisphere. Measurements in Europe included optical video imaging from a remote-controlled, semi-automatic camera system located at the Observatoire du Pic du Midi in the Pyrénées mountains in Southern France, infrasound observations from France, and ULF-HF electromagnetic observations from a number of locations. The measurements in South Africa included observations of optical emissions and VLF electromagnetic waves. The campaign was successful, with more than 100 sprites observed during 10 storms. The paper will give an overview of the campaign and some results. They include: (1) the first clear identification of infrasound from sprites, allowing independent (of optical observations) estimates of the energy input to the mesosphere, (2) the first detection of sprites triggered by intra-cloud lightning, a result that underscores the need for considering the complete thunderstorm source field resulting from both cloud-to-ground discharges and the intra-cloud discharges feeding them, and (3) a clear one-to-one relationship with sprites and early VLF events, suggesting that VLF ground transmitter signals can be an important tool for estimating ionisation and relaxation of ionised structures in sprites. No signatures of relativistic electrons were identified during the campaign.

Keywords: Atmospheric electricity; Lightning; Acoustic gravity waves; Mesospheric dynamics; Ionosphere/atmosphere interactions

\footnotetext{
*Corresponding author. Tel.: + 4535325731 ; fax: +4535362475 .

E-mail address: neubert@spacecenter.dk (T. Neubert).
} 


\section{Introduction}

Optical emissions in the region of the atmosphere above thunderstorm clouds are difficult to observe from the ground. While anecdotal evidence has been around for many years, emissions were first documented by scientists in 1989 above storms over the US plains (Frantz et al., 1990). The discovery sparked a flurry of interest in the scientific community, and now emissions of a wide variety are known to commonly exist. They include the "blue jet"-shooting up like a rocket from the top of thunderclouds through the stratosphere, the "sprite" - of gigantic flashes in the mesosphere at $40-80 \mathrm{~km}$ altitude, and the "elves" - with their rings of emissions at the lower edge of the ionosphere, propagating like ripples from a pebble thrown in the still waters of a lake.

Jets can be ignited spontaneously or in connection with a lightning discharge and represent a lightning stroke propagating upwards into the atmosphere from the cloud top. Sprites are directly related to the impulsive reconfiguration of space charge experienced during a lightning discharge, which is mediated by the associated impulsive quasi-static electric field propagating upwards through the atmosphere. Elves are the manifestation of the AC electromagnetic field generated by the lightning current, propagating isotropically from the source, and interacting with the partially ionised atmosphere at the lower edge of the ionosphere. More details on sprites, jets and elves - also referred to as Transient Luminous Events (TLEs)-are found in Neubert (2003) and references therein.

TLEs were first studied in the US, where powerful thunderstorms are generated over the plains during the summer. In Europe, observations began during the summer of 2000 with the deployment of an optical imaging system at the Observatoire du Pic du Midi in the Pyrénées mountains. Although the thunderstorms over Southern Europe generally are of lower power than the storms over the US, the system documented that sprites commonly occur over Southern France and Northern Italy (Neubert et al., 2001). The observations added further momentum to such European initiatives as the satellite project TARANIS (Tool for the Analysis of RAdiations from lightNIngs and Sprites) proposed for the French space agency micro-satellite program and recently selected for a detailed study phase, and the ASIM experiment (Atmosphere-Space Interactions Monitor) proposed for the International Space Station (ISS).

Further European initiatives include the MEIDEX experiment on the ill-fated mission of the Space Shuttle Orbiter that was lost during re-entry of the atmosphere in February 2002, but nevertheless having performed an interesting series of observations documenting TLEs over various regions of the earth (Yair et al., 2003, 2004; Israelevich et al., 2004). In addition, a precursor to the TARANIS optical experiment, the Lightning and
Sprites Observations (LSO) experiment, was flown on a number of occasions on the ISS (Blanc et al., 2004).

In 2002, the Research Training Network "Coupling of Atmospheric Layers" (CAL), was funded by the European Commission to study TLEs and their effects on the atmosphere. Under the collaboration, which includes 11 institutions and $8 \mathrm{Ph}$.D. students and post docs, annual European summer campaigns are organised with an increasing selection of complementary measurements. During the summer of 2003, the observations included:

1. Optical observations of TLEs over Southern Europe taken from the Pic du Midi. The data give the basic identification of TLE occurrences that other observations are interpreted against.

2. Observations by weather radars of cloud precipitation, giving basic information on meteorological conditions and on physical properties inside the cloud.

3. Information on lightning activity from lightning detection networks in Europe, provided in near-real time to the campaign. The data give information on cloud-to-ground (CG) lightning location, time, polarity, multiplicity, and peak current.

4. Information on intra-cloud lightning over a limited region in Province in Southern France, provided by the SAFIR system of lightning receivers. At least one storm generating sprites was located in the region.

5. Schumann resonance observations from Nagycenk, Hungary, providing information on charge moment (CM) changes associated with CG flashes.

6. VLF narrow band observations at Crete of 6 fixed frequency, ground-based transmitters located in Europe and Puerto Rico $(\sim 10-20 \mathrm{kHz})$. The signals propagate along great circle paths in the earth-ionosphere waveguide and are sensitive to perturbations in the lower ionosphere electron density.

7. VLF wide band observations from a receiver near Orleans, and $4 \mathrm{HF}$ receivers at different locations in France. The data give detailed information on the $\mathrm{CG}$ flash property and sprite radiation characteristics.

8. Infrasound observations from a location North-West of Paris. The data give information on the atmospheric heating associated with a sprite discharge.

9. Observation in the magnetic conjugate region over South Africa of optical emissions and VLF wave activity. The data are compared with TLE observations in the Northern Hemisphere in an attempt to identify signatures of relativistic electron beams injected into the magnetosphere in a sprite discharge, and precipitating in the Southern Hemisphere atmosphere.

The strategy of bringing together new combinations of instrumentation towards the common goal of exploring 
sprites and their effects on the mesosphere has been highly successful. The observations have underscored the limitations of our current understanding of the thunderstorm source field, as pointed out by observations of significant intra-cloud (IC) activity related to sprites. Another interesting result is the observation of infrasound from sprites. Such measurements have the potential to provide an independent means of quantifying the energy deposition to the mesosphere from sprites, a topic that has been discussed on the basis of optical measurements, with a wide range of energies deposited being proposed.

The ionisation of the mesosphere by sprites is also much discussed. Direct observations by radars are rare, and estimates are usually derived from optical spectral observations that are difficult to conduct and interpret because of atmospheric absorption effects, the proximity of emission lines, etc., or derived from ELF signatures from electric currents in sprites (Cummer et al., 1998). Observations of VLF wave propagation perturbation provide an independent means of quantifying the ionisation of the mesosphere by sprites. In the following we present an overview of the data taken during the campaign and discuss the themes suggested above in further detail.

\section{Optical observations}

In all, 10 storms were monitored from the Pic du Midi observatory during the 2 months of the campaign. The storms occurred at the beginning and end, with a period of almost one month in the middle, where a highpressure system caused a heat wave and drought over much of Europe, and were exceptional in that all instruments mentioned above had storms at the optimum geometry relative to the instrument location.

The video camera system at the Observatoire du Pic du Midi consists of two un-intensified, JAI CV-S3200 low-light CCD cameras based on the Sony ICX248AL $1 / 2^{\prime \prime}$ monochrome ExView HAD sensor. The cameras are equipped with two identical $16 \mathrm{~mm} \mathrm{F1.4} \mathrm{lenses} \mathrm{with}$ a field-of-view of $22.5^{\circ}$ and are mounted in a weatherproof housing on top of a motorised pan/tilt unit. All images and video files are time stamped using the PC system time that is synchronised to UT time through the Network Time Protocol (NTP). The system time is correct within $12 \mathrm{~ms}$. The PC clock is synchronised every $10 \mathrm{~min}$.

The system is controlled via the Internet. It includes trigger software for automated flash detection running on the data stream from one of the cameras, the "event" camera. The algorithm flags images of impulsive optical activity for transmission to a computer at the Danish Space Research Institute (DSRI), where the image is made accessible together with real time lightning information through a web-interface. The data from the "pan" camera is continuously stored on a local disk at the Pic du Midi, and downloaded to DSRI during the daytime. More information on the system is found in Allin et al. (2004).

During the campaign, 101 sprites and 2 elves were captured. The sprites came in all the forms known from past campaigns such as the "columniform"- or csprites, carrot sprites, clusters of sprites, dancers, etc. Most of the sprites were seen in one video frame only, with 10 events extending to multiple frames. An example of a complex sprite observed on August 28 at 23:16:55.809 UT at $529 \mathrm{~km}$ distance over the Province region of France is shown in Fig. 1a. The emission region extends $\sim 100 \mathrm{~km}$ in the horizontal direction, and includes both the classical carrot-shape sprite, and a significant number of c-sprites at regular intervals of $\sim 10 \mathrm{~km}$. For comparison, the overall structure of the electric field in the upper atmosphere following a $+\mathrm{CG}$ is shown in Fig. 1b. The field is normalised by the threshold field required for electrical break down and is calculated assuming a discharge of a positive pointcharge at $8 \mathrm{~km}$ altitude of $1000 \mathrm{C}$ during $3 \mathrm{~ms}$ at the time $1 \mathrm{~ms}$ after the end of the discharge. Comparing Figs. 1a and $b$ one recognises that the overall envelope of the sprite emission region corresponds well to the geometry of the region of large normalised fields, demonstrating that our basic concepts for sprite generation probably are correct.

Sprites are often significantly displaced horizontally from the causative $+\mathrm{CG}$, at times up to $\sim 50 \mathrm{~km}$ or more (Lyons, 1996; São Sabbas et al., 2003). At first glance this seems to be in contradiction with our zero-order understanding of the sprite discharge, where the field is largest directly above the $+\mathrm{CG}$ flash, and this region is the most likely to harbour sprites. One explanation put forward suggests that spider lightning, which runs for considerable distance within a cloud, may feed the causative $+\mathrm{CG}$, and that the source field in the mesosphere is a result of the impulsive reorganisation of space charge in a thundercloud layer of considerable horizontal extent and not just from a point charge as assumed above. As we shall see later, the data from the EuroSprite2003 campaign supports the view that the complete discharge field from both the intra-cloud (IC) discharges related to a $+\mathrm{CG}$ and the $+\mathrm{CG}$ itself must be considered. However, it is also clear that the horizontal displacement need not be a result of this process. Consider the sprite, observed on July 23 at 23:21:41.127 UT, shown in Fig. 2a. It is displaced $\sim 20 \mathrm{~km}$ horizontally from the causative lightning, which is seen as illumination of the cloud at the bottom of the image. The sprite is curved, with the lower tendrils reaching towards the centre of the cloud illumination. This structure is consistent with the electric field direction expected over a point-or "small" space 

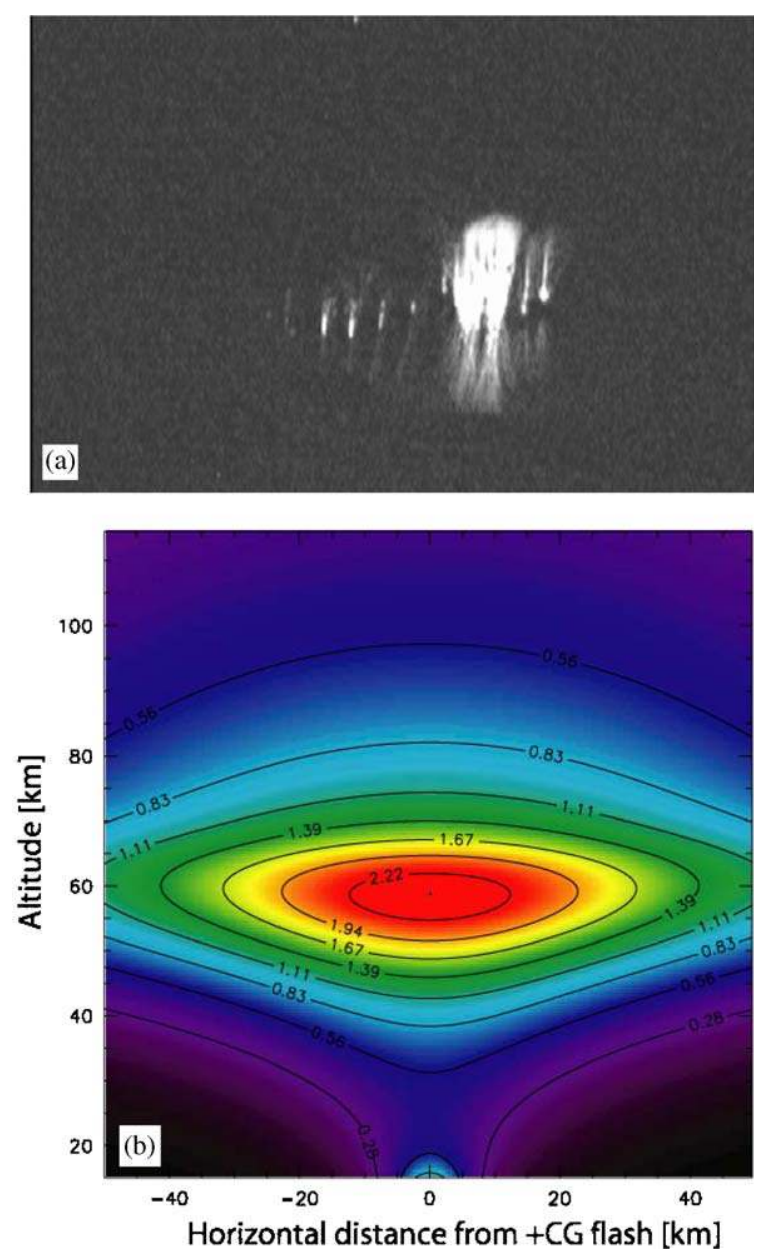

Fig. 1. The oval-shaped, large-scale region containing sprite emissions reflects the zero-order region of high quasi-electrostatic fields following a +CG. (a) Cluster of sprite emissions extending $\sim 100 \mathrm{~km}$ horizontally with significant structure on medium-scale of c-sprites; observed on August 28 at 23:16:55.809 UT. (b) Theoretical estimate of the electric field normalised by the threshold field for electrical breakdown $1 \mathrm{~ms}$ after a $+\mathrm{CG}(1000 \mathrm{C}$ from $8 \mathrm{~km}$ in $3 \mathrm{~ms})$.

charge region in the cloud as shown schematically in Fig. $2 b$ at a time prior to discharge. In this very simplistic view of a thunderstorm charge distribution the upper regions of the cloud are positive and the lower region negative. The positive upper layer, shown as the "red" pole, is connected to the ionosphere above, which is a good electric conductor. As the positive pole discharges to the ground during a $+\mathrm{CG}$, the electric field reconfigures by changing direction, pointing from the ionosphere towards the negative pole. As an electrical discharge in the atmosphere is dominated by the electric field (at least below $70 \mathrm{~km}$ altitude for eVenergy electrons), streamers propagate in the direction
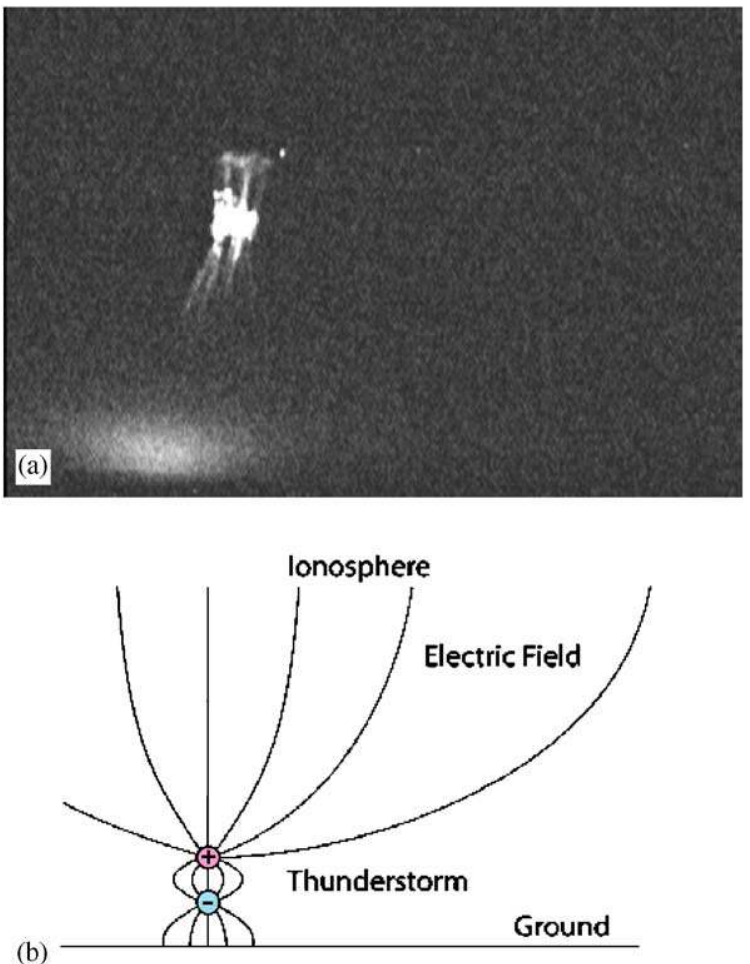

Fig. 2. The sprite orientation reflects the instantaneous local electric field direction. (a) Sprite above cloud illuminated by lightning on July 23 at 23:21:41.127 UT. (b) A schematic illustration of the electric field topology above a thunderstorm.

of the instantaneous electric field. Thus the grossfeatures of a sprite will trace the zero-order direction of the electric field above the thunderstorm.

However, the question remains why the sprites, such as the one shown in Fig. 2a, are not centred above the causative $+\mathrm{CG}$, and why sprites contain such rich structure. It has been proposed that the medium-scale structure (kilometres) of sprites, seen as the occurrence of c-sprites in Fig. 1a, is related to the properties of the mesosphere rather than the thundercloud source. Recognising that the threshold electric field for breakdown scales as $E / p$, the so-called "reduced field", where $E$ is the electric field and $p$ is the atmospheric pressure, it is proposed that gravity waves, expected over thunderstorms where strong upward convection perturbs the atmosphere above the troposphere, are likely candidates to provide a structured modulation of the density, with the reduced field above the threshold in the density wave minima (Sentman et al., 2003; Snively and Pasko, 2003).

Alternate suggestions for the source of the kilometrescale structure invoke the IC component of a lightning flash. Assuming a fractal antenna approximation to the IC discharge current, calculations show constructive interference patterns in the mesosphere with regions of 
high field intensities at horizontal scales of a $\sim 10 \mathrm{~km}$ (Valdivia et al., 1998). In this approach, it is further shown that the field in the mesosphere from the IC is relatively larger than the quasi-electrostatic field from a $+\mathrm{CG}$, and therefore only requires $\sim 100 \mathrm{C}$ of redistributed charge to excite a field above the threshold. A different approach, invoking a linear, horizontal IC discharge, includes the effects of reflection of the electromagnetic pulse from the surface of the earth and the bottom of the ionosphere. Also in this case, regions of constructive interference are created in the mesosphere with scales of $\sim 10 \mathrm{~km}$ (Cho and Rycroft, 2001). It is further shown that the EMP can be of a magnitude to create significant ionisation enhancement of the bottom ionosphere, suggesting that if the IC flash feeds a +CG flash, the quasi-static electric field following the $+\mathrm{CG}$ will drive sprite streamers initiated in the regions of constructive interference (Roger et al., 2001).

We note here, that the scales suggested by both gravity waves and IC electromagnetic fields seem in agreement with the sprite observation shown in Fig. 1a. Furthermore, data from IC activity observed by the SAFIR system supports the view that IC activity can be important for sprite generation, as will be shown later.

Turning now to the fine-structure of sprites, an example taken on August 24, 21:17:41.911 UT at $204 \mathrm{~km}$ distance from the Pic du Midi is shown in Fig. 3a. It contains single filaments with beads and branches, known from telescopic imaging to reach scales below tens of meters (Gerken et al., 2000; Mende et al., 2002). The fine-structure in part reflects the grainy nature of the mesosphere, which is constantly bombarded by ionising cosmic rays or meteorites creating trails of ionisation and deposition of metallic particles thought to form the seeds of electrical discharges (Symbalisty et al., 2000; Zabotin and Wright, 2001). Small-scale pockets of ionisation or metallic particles may have the effect of amplifying the background electric field. For instance, a local pocket of plasma will polarise in the quasi-static electric field, screening out the field inside the pocket and amplifying the field at the edges as shown schematically in Fig. 3b. The enhanced field at the space charge layers, when above a threshold, may allow a streamer to be formed. Once formed, a lower field is required to sustain streamer propagation.

The details of sprite ignition, as many aspects of electrical discharges, are not well understood and awaits advances in modelling, laboratory experiments, and instrumentation, in particular high-speed imaging that allows the resolution of streamer head emissions above the present speed limit of $1 \mathrm{kHz}$ frame rate reported in Stanley et al. (1999); Stenbaek-Nielsen et al. (2000). However, as illustrated with the above interpretation of observations with zero-order-, medium-, and fine-scale models, it is clear that understanding the sprite discharge
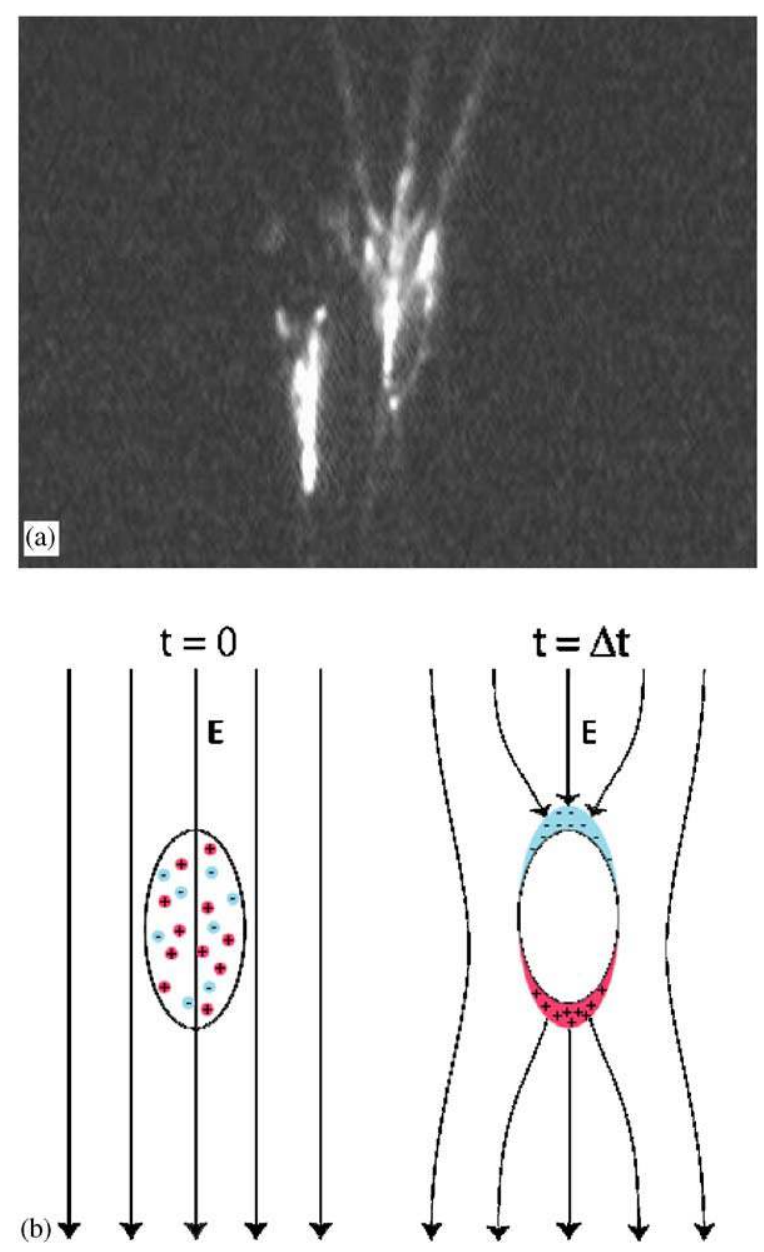

Fig. 3. The fine-structure of sprites reflects the seed mechanism of sprite ignition with the formation of streamers. (a) Smallscale structure of sprite observed at $202 \mathrm{~km}$ distance on August 24, 21:17:41.911 UT. (b) A schematic illustration of a seed mechanism for sprite ignition. Left: A small pocket of preionised atmosphere - perhaps from cosmic ray ionisation - at the time of turn-on of an ambient electric field. Red denotes positive ions and blue negative electrons. Right: The initial response of the space charge in the plasma pocket, which polarises, cancelling the electric field inside and amplifying the field at the space-charge layers.

process holds the promise of new insights into, and appreciation of, the physics of the mesosphere - the least known region of the atmosphere.

\section{Intra-cloud and cloud-to-ground lightning generation of sprites}

The thunderstorm of 23 July is of particular interest as it crossed the area covered by the SAFIR system in the South-East of France, allowing detection of IC activity. 
In addition, the convective system was analysed by means of meteorological radar data and Meteosat satellite data on cloud cover and cloud top temperatures. The CG flash activity was detected both by the SAFIR system (when inside the region of coverage) and by the French network Météorage.

During the storm, 13 sprites were detected between 2111 UT and 0033 UT on 24 July. All sprites, except one, could be associated with $+\mathrm{CGs}$, confirming the results of past studies that the vast majority of sprites are triggered by +CGs (e.g. Lyons, 1996). They occurred in a relatively small portion of two storm systems with the sprite-associated +CGs clustering in a small area. This suggests that rather special conditions are required for sprite production to take place, and that these conditions are met only in limited "sprite-producing cells" of some storms.

The sprite-associated +CGs were located outside the dissipating high-reflectivity core in the stratiform region of the storm system (often several tens of $\mathrm{km}$ from the centre of the storm). Meteosat images showed that sprites seem to occur only in regions with cold (high) cloud tops in the vicinity of the tropopause. The sprites had a tendency to occur fairly regularly with a few minutes interval, as if, at certain precise moments of the storm, favourable conditions for the sprite process were present. On the other hand, the sprite production started in a late stage of the two storm areas when the $-\mathrm{CG}$ and IC activities were rapidly falling, but the $+\mathrm{CG}$ activity remained stable or even increased slightly. This observation corresponds also with previous works (e.g. Lyons et al., 2003). We observed a pattern where the sprite generation seemed to be correlated, not to the number of + CGs itself, but to the ratio of positive CGs to the total number of CGs. Some of the sprites occurred at a stage when the CG activity was close to zero and almost all of the few CGs that actually were detected at that moment had positive polarity.

The intra-cloud (IC) detecting system, SAFIR, shows in most cases the presence of intense IC activity during the second before and/or after a sprite. The large number of VHF sources associated with a flash at these moments indicates complex IC discharges, which could be associated with some phases of the +CG stroke detected at the same moment. For several sprites, the IC activity was very low during the minute before and after the sprite, but with an abrupt peak at the moment of the sprite.

For one sprite, observed at 21:34:58.160 UT, no CG flash was identified. The sprite is shown in Fig. 4a and the location of the IC activity in the second prior to the event in Fig. 4b. The IC activity has a modest horizontal extent unlike other cases where the VHF sources associated with an event were distributed over large distances. The red lines marked on Fig. $4 \mathrm{~b}$ indicate the direction of the two sprite elements seen from the Pic du (a)
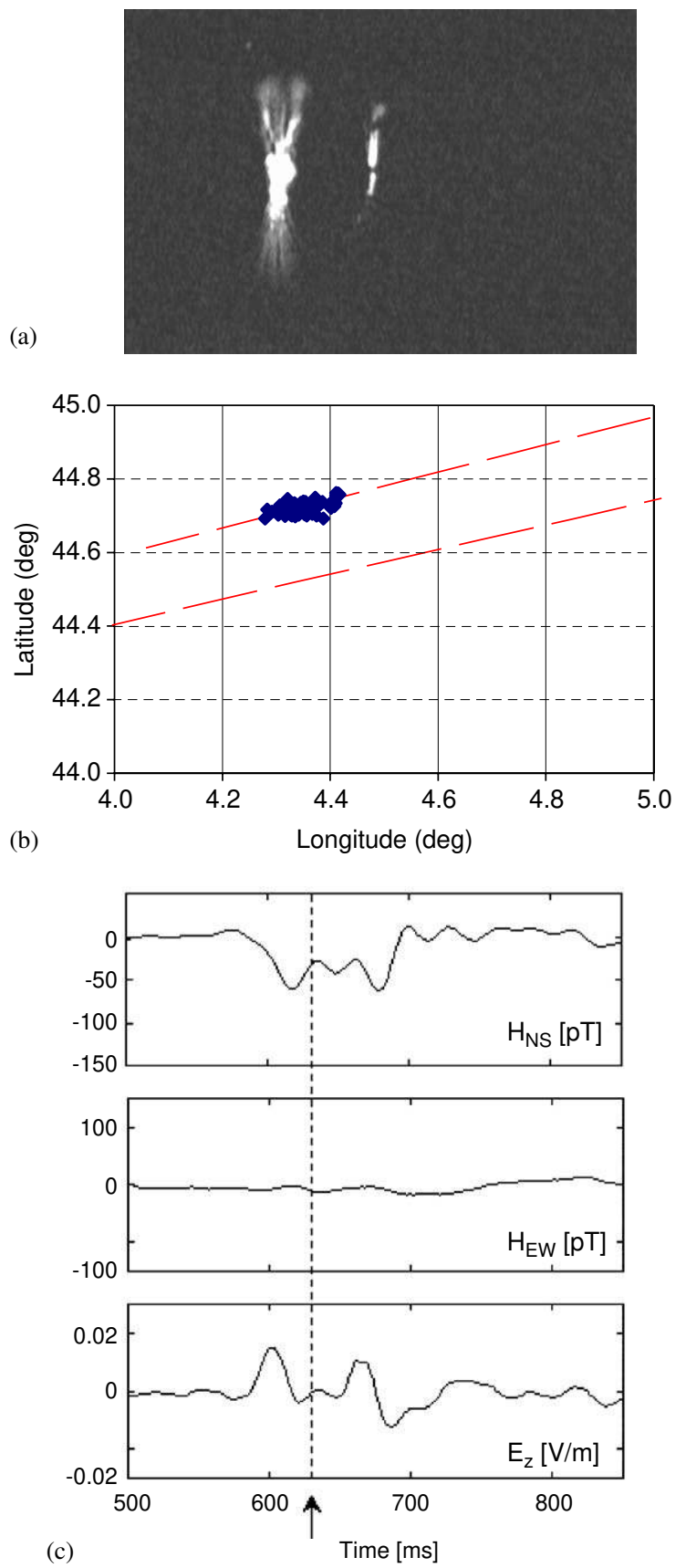

Fig. 4. Sprite generated by IC discharges. (a) Sprite on July 23 at 21:34:58.160 UT. (b) Geographic location of the corresponding IC discharge of 70 elements observed by the SAFIR system (blue), and the direction of the two sprite elements observed from the Pic du Midi (red). Upper curve corresponds to the large carrot sprite and the lower curve the smaller sprite. (c) SR transients recorded at Nagycenk, Hungary. Dashed line indicates the time of the sprite. The charge moment change is $\sim 800 \mathrm{Ckm}$ computed from the SR transient following the sprite. 


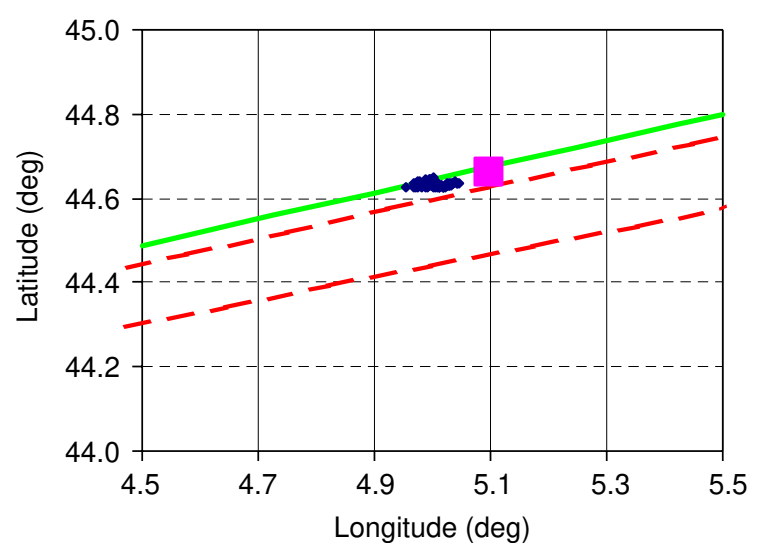

Fig. 5. Lightning activity related to the sprite shown in Fig. 2. Blue marks IC elements and red the $+\mathrm{CG}$. Red lines mark the left and right edges of the sprite seen from the Pic du Midi and green the centre of the cloud illumination.

Midi. The top one corresponds to the larger element and clearly corresponds very well with the location of the IC activity. The smaller element is curving towards the larger element location at low altitudes, consistent with the interpretation given above of horizontally displaced sprites (Fig. 2). Since neither the Météorage nor the SAFIR system detected CGs during the second before this sprite, we assume it was triggered by the IC flashes.

The lightning activity related to the horizontally displaced sprite of Fig. 2 is shown in Fig. 5. The red lines mark the horizontal boundaries of the sprite seen from Pic du Midi and the green line the centre of the illuminated cloud. In this case, both +CG and IC activity was observed. As seen from the figure, the horizontal displacement is consistent with the interpretation of the zero-order electric field structure above a thunderstorm as discussed in connection with Fig. 2.

A detailed study of the IC activity for many sprites is necessary to provide a more clear understanding of the relationship between the thunderstorm discharges and the sprite phenomenon. However, the observations presented above point out that a key parameter is the mapping of the VHF sources to determine the redistribution of the charge in a flash. Unfortunately, information on IC discharges is rarely available.

\section{Charge moments related to sprites}

The CM change of a discharge is the amount of charge times the distance it has been moved. This parameter has been shown to be more relevant in quantifying the ability of a flash to generate TLEs than the often measured peak current of a discharge (Huang et al., 1999). Electromagnetic waves radiated by a discharge in the lowest band of the ELF range can excite the earth-ionosphere cavity. The resonance frequencies, known as Schumann resonances (SR) (Schumann, 1952), are determined by the effective circumference of the earth and the phase speed of electromagnetic waves in the earth-ionosphere waveguide. The fundamental resonant frequency is close to $8 \mathrm{~Hz}$, with higher-order modes spaced at intervals of about $6 \mathrm{~Hz}$. Energetic lightning discharges excite the cavity, and the pulsed discrete variations, lasting for a fraction of a second, appear as coherent signals in the vertical electric and horizontal magnetic field components superimposed on the background ELF noise. From these SR transients, one can estimate the CM change of a flash.

SRs were detected during the campaign in the frequency band $5-30 \mathrm{~Hz}$ at Nagycenk, Hungary $\left(47^{\circ} 37^{\prime} \mathrm{N}, 16^{\circ} 43^{\prime} \mathrm{E}\right)$. The $\mathrm{CM}$ changes associated with the +CGs that were identified for sprite events were calculated by using one of the methods described by Huang et al. (1999), which assumes an exponential decay of the lightning current. Spectra of the SR field components depend on the source-observer distance, which is known from lightning detection networks. The ratio of the observed and theoretical spectra of each SR field component computed for the distance of the causative flash gives the current moment spectrum of the discharge. CM estimation is based on finding that exponential function for which the Fourier transform gives the best approximation of the current moment spectrum (Burke and Jones, 1996; Huang et al., 1999).

Theoretical spectra are calculated assuming a vertical dipole discharge approximation (Wait, 1962), and EM wave propagation from the source to the observer in the earth-ionosphere waveguide with a perfectly conducting ground and an ionospheric conductivity that is isotropic and given by the mean of three conductivity profiles (Jones, 1967). The method has been shown to give good correspondence between measured and observed spectra (Jones and Kemp, 1970). An example of a sprite over South-Eastern France on August 28 at 23:11:10.839 UT, and the SR transient from the causative $+\mathrm{CG}$, is shown in Fig. 6. The CM change estimated for this event is $2200 \mathrm{C} \mathrm{km}$.

The distribution of CM change estimates is shown in Fig. 7. Out of the 101 TLE events, 76 SRs were suitable to deduce CM changes. Some had to be discarded, not because of lack of EM signal, but because the TLE events were associated with multiple CGs and thus the EM signatures were too complex for the method adopted. The largest value reached is about $4500 \mathrm{C} \mathrm{km}$, while the typical values are about $300-700 \mathrm{Ckm}$. Although a variety of methods exist to estimate the $\mathrm{CM}$ changes, some of them invoking EM radiation well above the SR band, the values shown here compare well with other estimates related to sprite generation (Huang et al., 1999; Hu et al., 2002). 

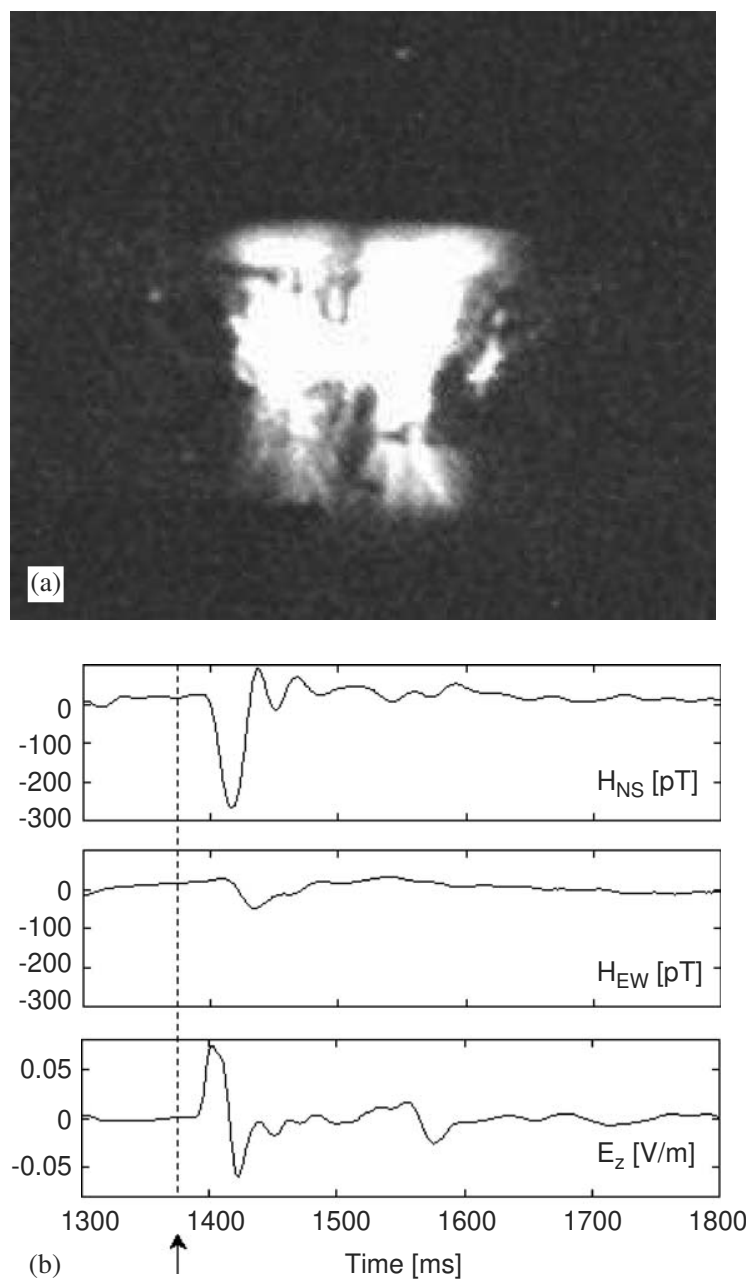

Fig. 6. (a) Sprite on August 28 at 23:11:10.839 UT. (b) SR transients recorded in the horizontal magnetic ( $H_{\mathrm{NS}}$ and $\left.H_{\mathrm{EW}}\right)$ and vertical electric $\left(E_{\mathrm{Z}}\right)$ field components at Nagycenk, Hungary. The estimated charge moment change is about $2200 \mathrm{C} \mathrm{km}$. The arrow and dashed line mark the time of sprite.

SR transients were also observed in those few cases, when no CG could be identified, including the event shown in Fig. 4a, where two independent lightning detection networks both did not detect CGs, and one (SAFIR) recorded significant IC activity. The SR signature presented in Fig. 4c indicates overlapped transients (due to at least two +CG-like events) from the same thunderstorm region as the same direction was inferred from the Poynting vector computed from the electric and magnetic field components before and after the sprite. It is assumed that the SR transient, starting before the sprite, was excited by an IC flash as neither of the lightning detection systems recorded $+\mathrm{CG}$ and the SAFIR system showed strong IC activity in a well confined region.

\section{Sprite ionisation of the mesosphere}

The Crete VLF receiver, located at $35.31^{\circ} \mathrm{N}$ and $25.08^{\circ} \mathrm{E}$, began operation on July 18,2003 , shortly before the start of the EuroSprite2003 campaign. It is capable of monitoring $6 \mathrm{VLF}$ transmitters chosen from those available around the globe for navigation purposes. The Crete VLF station consists of a receiver identical to those of the Holographic Array for Ionospheric Lightning (HAIL) system in the United States (Johnson et al., 1999). The wideband signal is detected with a $1.7 \times 1.7 \mathrm{~m}^{2}$ magnetic loop antenna and is sampled at $100 \mathrm{kHz}$ with 16 -bit resolution and with GPS-based timing. The sampled waveform is then digitally filtered into 6 narrow bands centred close to the transmitter frequencies. Five of the selected transmitters were in Europe and one in Puerto Rico. The 6 transmitter call-signs, their frequencies, and the corresponding great circle paths (GCP) to the receiver are shown in Fig. 8. The system provides continuous monitoring of the phase and amplitude variations, which reflect changes of ionisation properties in the lower ionosphere and upper atmosphere along the signal path.

The receiver worked properly until August 5, and thus covered only part of the campaign period during which nearly 50 sprites were recorded. In the following are given highlights of studies of a mesoscale thunderstorm system on 21 July 2003 over Central France, when 28 sprites were observed during a 75-min period from about 0200 to $0315 \mathrm{UT}$. More details are found in Haldoupis et al. (2004).

The approximate storm location and extent is indicated in Fig. 8 by the small shaded area at about $46^{\circ} \mathrm{N}, 3^{\circ} \mathrm{E}$. The storm was $150-200 \mathrm{~km}$ southeast of the HWV (Le Blanc, $46.7^{\circ} \mathrm{N}, 1.26^{\circ} \mathrm{E}$ ) and HWU (Rosnay, $\left.46.6^{\circ} \mathrm{N}, 1.1^{\circ} \mathrm{E}\right)$ VLF transmitter sites, and about $2200 \mathrm{~km}$ from Crete. The GCPs to Crete of the HWV and HWU transmitters passed right through the storm region.

The amplitude of one of the VLF signals that passed through the ionosphere above the sprite-producing storm exhibited rapid onset perturbations occurring in a nearly one-to-one relationship with the optical sprites. These "Early" VLF events are consistent with a process of narrow-angle forward scattering from a volume of enhanced ionisation above the storm with lateral sizes larger than the VLF radio wavelength, that is, larger than about $30 \mathrm{~km}$ (Dowden et al., 1996). The many positive and negative CGs that did not trigger sprites were also not associated with detectable VLF amplitude perturbations, even though some of these discharges reached relatively large peak currents.

The rapid onsets of several of the sprite-related VLF perturbations were followed by a relatively long growth period, ranging from about 0.5 to $2.5 \mathrm{~s}$, indicating that 


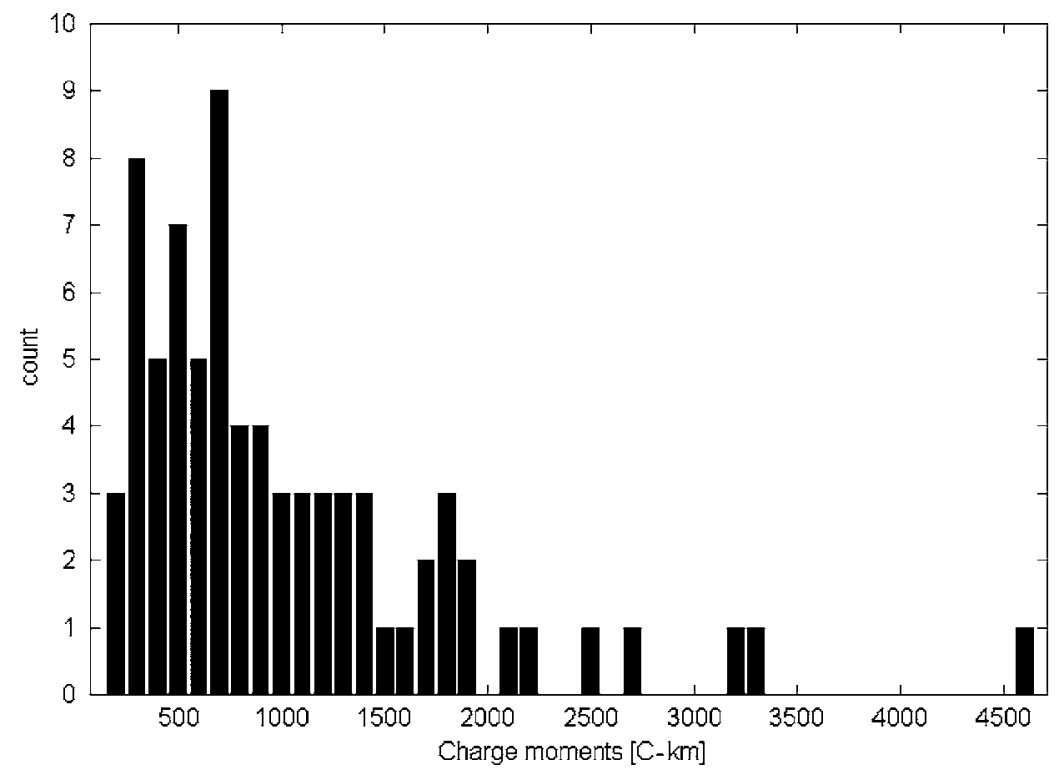

Fig. 7. Histogram of charge moment (CM) changes deduced from 76 sprite producing Schumann resonance (SR) transients observed at Nagycenk, Hungary.

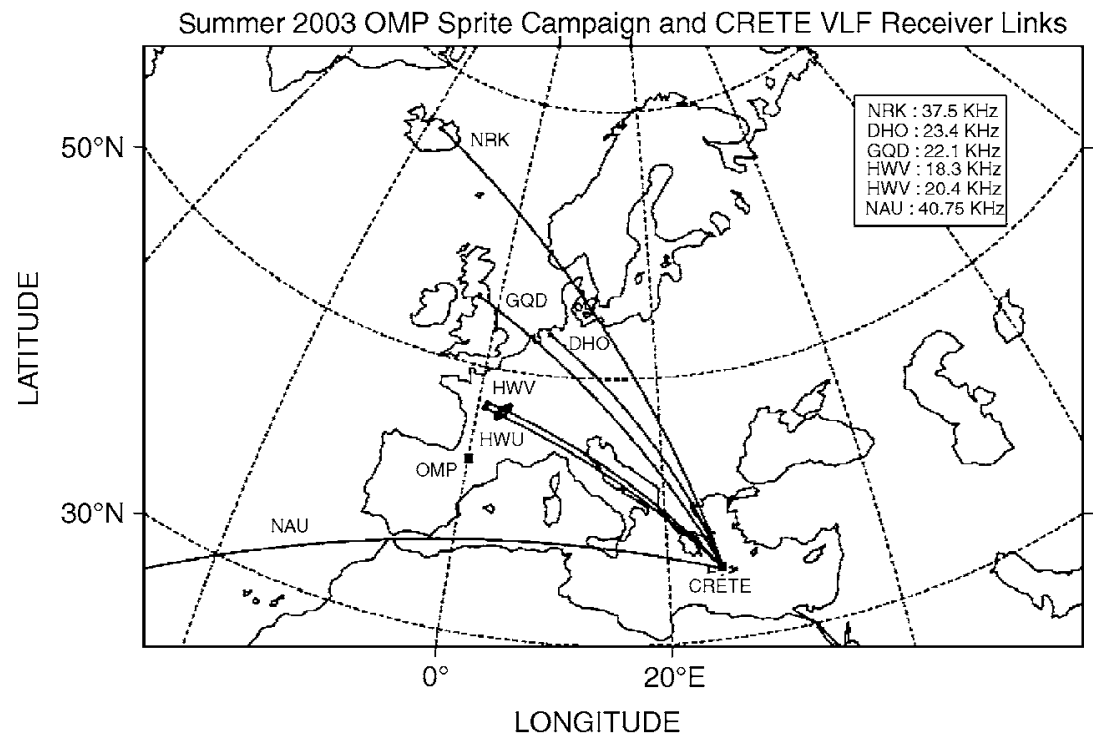

Fig. 8. VLF transmitter signal great circle paths to the receiver at Crete. The thunderstorm observed on July 21, 2003, is marked by the shaded area overlapping the paths of signals from the two French receivers HWV and HWU (Haldoupis et al., 2004).

these events were Early but not "fast". These "Early/ slow" events suggest a slow process of ionisation buildup in the lower ionosphere, following intense lightning discharges that also lead to sprites. An example of this "Early/slow" VLF signature that occurs in association with a sprite observed on July 21 at 02:35:00:000 is shown in Fig. 9. This new signature constitutes an unexpected and intriguing observation, which is not understood. Also, a limited number of early VLF perturbation events were associated with whistlerinduced electron precipitation events, or classic Trimpi perturbations, undoubtedly produced by the 

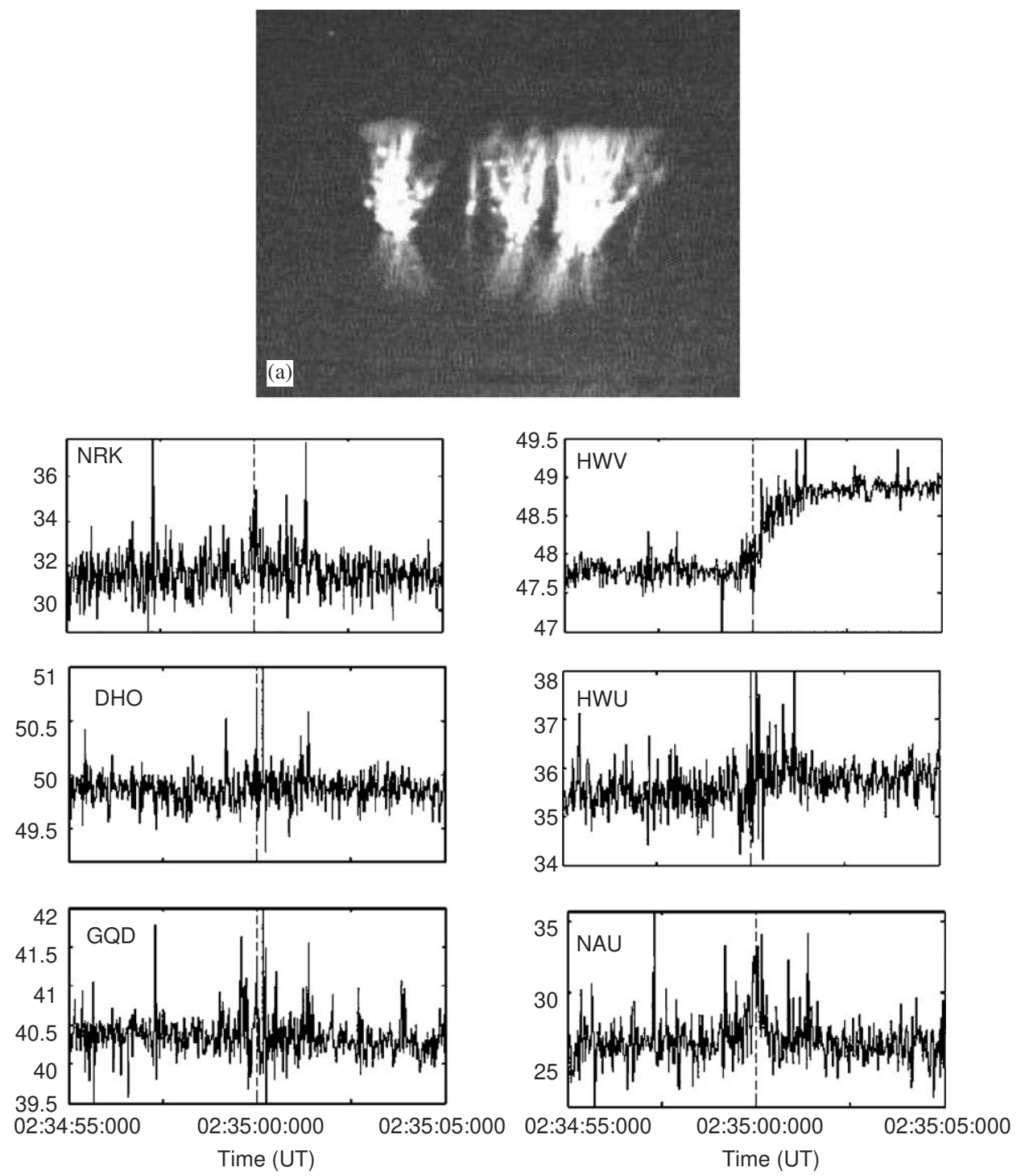

Fig. 9. Ionisation of the atmosphere by sprites. (a) Sprite observed on July 21 at 02:35:00:000 UT. (b) Perturbations in signal power as a function of time observed at Crete. The time of the sprite is marked by the dashed lines. The rise of perturbation in HWV is instantaneous and "slow" indicating that the ionisation builds up over $\sim 2 \mathrm{~s}$, followed by an even slower decay.

precipitation of electrons due to whistler-mode waves injected into the magnetosphere by the same lightning flash that led to the production of the sprite.

\section{Infrasound from sprites}

Infrasound observations were performed from Flers in Normandy (France), about $300 \mathrm{~km}$ North-West of Paris. The infrasound station is composed of four microbarometers MB2000, which measure the local relative pressure with a sensitivity of $10^{-3} \mathrm{~Pa}$, a band pass of $0.01-27 \mathrm{~Hz}$, and a sampling frequency of $20 \mathrm{~Hz}$ (Le Pichon et al., 2002). The measurements were performed to test instruments and methods and to identify natural infrasound sources in the frame of the Comprehensive Test Ban Treaty verification (Vivas Veloso et al., 2002). During the EuroSprite2003 campaign a clear sprite signature was identified in the infrasound signals as chirped burst of a few seconds duration (Farges et al., 2005). The association of bursts to sprites was done by calculating the time of arrival of 
an acoustic wave produced by a sprite between 60 and $80 \mathrm{~km}$ altitude. This calculation uses the location of the +CG parent lightning and a paraxial ray-tracing model (Virieux et al., 2004) including realistic sound velocity and wind speed profiles (Hedin et al., 1996). The potential ambiguity of source identification, sprite vs. the causative lightning flash, is avoided because all the storms considered in the summer of 2003 were too distant for lightning flashes to be observed as the detection limit for infrasound produced by lightning is $\sim 50 \mathrm{~km}$.

An example of a sprite observed over Corsica at 21:50:22.065 UT on August 25, is shown in Fig. 10a and a 1-min interval of the relative pressure signal and the corresponding spectrogram in the $1-9 \mathrm{~Hz}$ spectral band measured from 22:53:50 UT in Fig. 10b. The $1-9 \mathrm{~Hz}$ spectrogram shows the chirp-like feature with the low frequencies arriving before the high frequencies, as has been suggested in Liszka (2004). During the campaign, the sprite detection efficiency of the infrasound system was $\sim 70 \%$ with a maximum distance of detection $\sim 1000 \mathrm{~km}$ or more. It was further found that the duration of the infrasound bursts correlate with the horizontal size of the sprites, and reflects the travel time of infrasound across the sprite. During one period of observation, sprites continued to appear in the infrasound signal even beyond sunrise when optical observations were no longer possible and continued until $\sim 12$ UT.

\section{Search for relativistic electrons}

It has been proposed that sprites are initiated by an energetic run-away electron avalanche accelerating electrons to $\mathrm{MeV}$-energies, and that beams of energetic electrons are injected into the magnetosphere from the top of the atmosphere above sprites (Roussell-Dupre and Gurevich, 1996). Once in the magnetosphere, the beam will undergo pitch angle- and energy scatting, and a portion will precipitate in the conjugate atmosphere,
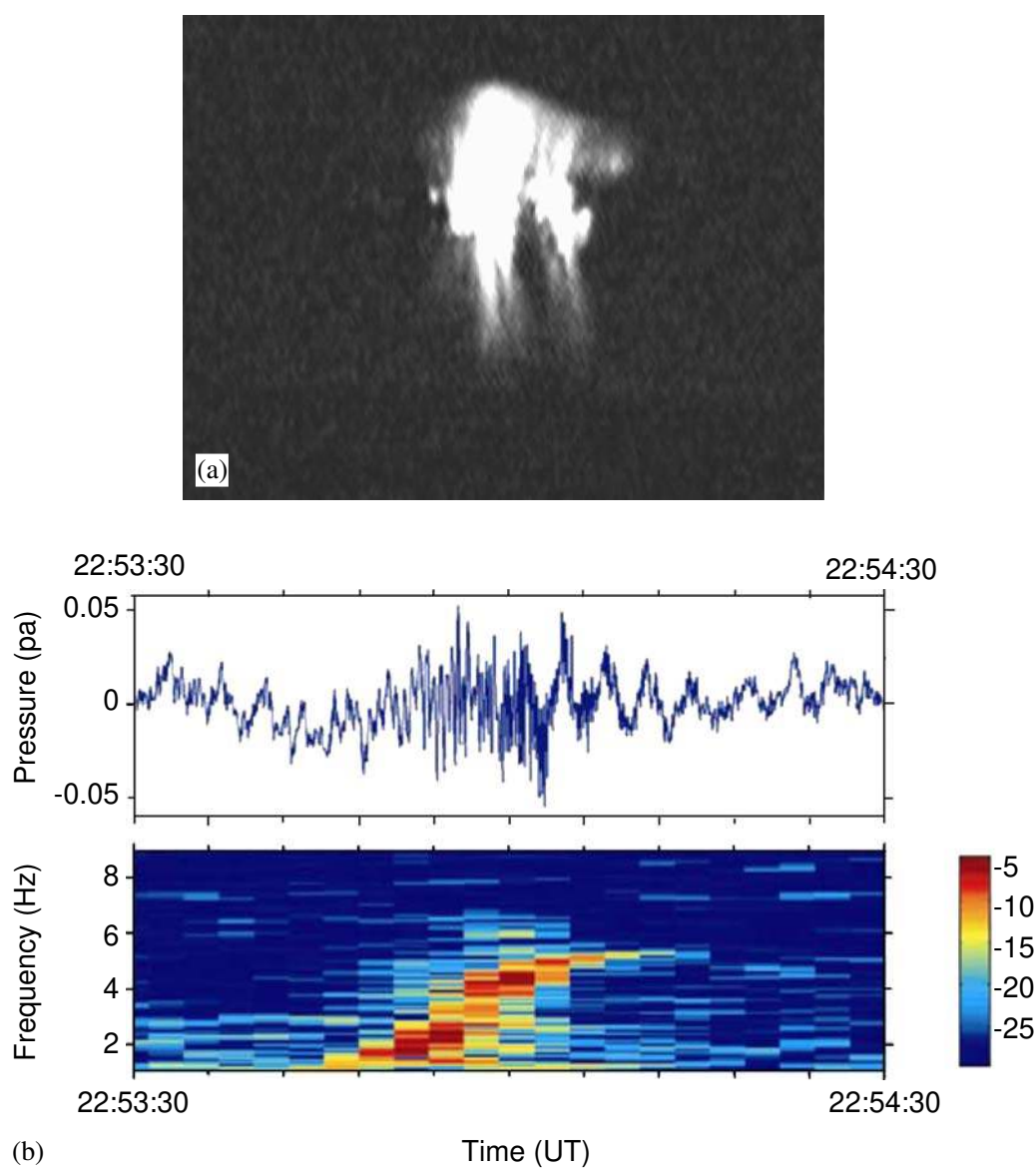

Fig. 10. Infrasound from sprites. (a) Sprite observed over Corsica on August 25 at 21:50:22.065. (b) Pressure perturbations and sonogram of infrasound observed at the Flers station $300 \mathrm{~km}$ North-West of Paris. 
enhancing electrical conductivity, and generating $\gamma$-rays and optical emissions (Lehtinen et al., 1999).

The Wide-angle Array for Sprite Photometry (WASP) was deployed at the South African Astronomical Observatory (SAAO), near Sutherland $\left(20^{\circ} 48^{\prime} \mathrm{E}\right.$, $32^{\circ} 22^{\prime} \mathrm{S}, 1759 \mathrm{~m}$ ), to attempt to detect optical emissions from relativistic beams of electrons. The WASP is an array of six photometers with $3^{\circ} \times 6^{\circ}$ fields-of-view, 1 kiloRayleigh (kR) sensitivity in the band from 665 to $900 \mathrm{~nm}$, and $25 \mathrm{kHz}$ temporal resolution. The fields-ofview are arranged in a 2-by-3 non-overlapping format to yield maximum sky coverage. The WASP and the conjugate experiment are described more fully in Marshall et al. (2004).

The experiment detected no emissions even though two storms were in good geometric location relative to the WASP instrument with good local weather conditions. The most likely explanation is the lack of sensitivity of the measurement relative to the magnitude of the event. The sensitivity is given by the background of the night sky, which is $1 \mathrm{kR}$ in the band observed, the molecular nitrogen, first positive band. Models of the effects on the conjugate atmosphere of relativistic electron beams injected above sprites estimate that $\sim 10 \%$ of the electron beam scatters into the loss cone during the first transition of the magnetosphere (Lehtinen et al., 2001). The relationship between the electron beam density injected into the magnetosphere and the electric field in the mesosphere following a $+\mathrm{CG}$ is highly non-linear. Assuming for instance a cloud electric field structure with point charge regions as shown in Fig. $2 \mathrm{~b}$ and with the upper positive pole at $10 \mathrm{~km}$ altitude, the emission rates at the conjugate hemisphere predicted from the model of Lehtinen et al. (2001) reach $1 \mathrm{kR}$ for $600 \mathrm{C}$ charge removed and $1 \mathrm{MR}$ for $800 \mathrm{C}$. As seen from Figs. 3 and 5, CMs are primarily in the range $100-2000 \mathrm{C} \mathrm{km}$ and below the threshold of $6000 \mathrm{C} \mathrm{km}$ predicted by theory.

Broad-band VLF and narrow-band Omnipal VLF measurements were made at the SAAO in support the WASP experiment. The system consisted of two vertical crossed-loop rhombic antennas orientated geographic North-South and East-West (Collier and Hughes, 2002). A number of instances of whistlers generated by lightning strikes in Europe were identified in the broadband data, but no signature that could be identified specifically with sprites or with relativistic electron beam precipitation over the conjugate region.

The Omnipal system detects phase and amplitude perturbations on signals from ground transmitters, propagating in the earth-ionosphere waveguide, as did the system on Crete described earlier. The system is used normally to detect wave-induced particle precipitation events (e.g. Friedel et al., 1993). The signals from 4 stations were monitored: NAA, NLK, FRA and NWC. The great circle paths for the first three of these passed through or near to the regions in which relativistic electron precipitation was expected. However, no signatures of precipitation could be associated with any of the sprites detected during the campaign.

\section{Conclusions}

The campaign successfully brought together new combinations of instruments giving new science. For the first time, intra-cloud (IC) lightning has been shown to generate sprites. It is known that sprites commonly are associated with positive cloud-to-ground $(+\mathrm{CG})$ discharges and rarely with -CGs or no CGs. As the networks are sensitive only to CGs and not to the primarily horizontally stratified IC, it has not been possible until now to estimate the role of ICs in the sprite generation process. It is not known, for instance, if the events in the past, were no CG was identified, were caused by a failure of the networks to detect a CG or because IC discharges really were the source. In any case, it is clear that ICs play an important role defining the source field and that techniques to measure the IC component are very important. It is also clear, that models of the source field need to account for this more realistic source distribution, as some efforts have attempted to do.

The discovery of a clear infrasound signature from sprites has the potential, together with techniques based on the electromagnetic signature, to detect sprites during the daytime where optical observations cannot be performed. At this point in time, either of the two techniques by themselves may not have the confidence of optical observations, but taken together, daytime observations of sprites may give useful and believable information. This is of great interest as one of the important parameters of sprite physics, the atmospheric electrical conductivity profile, is changing dramatically from night to day. Daytime observations of sprites may therefore give new insights into the basic physics of sprites.

Infrasound observations further have the potential to provide estimates of the energy deposited to the atmosphere by sprites. Estimates have been given in the past based on optical observations, but are difficult because of atmospheric absorption properties, the proximity of important emission lines, etc. Taken together, consistent estimates from two different types of observations will give us confidence in both.

A new result from the VLF ground transmitter experiment from Crete is the discovery of "Early/slow" VLF perturbation associated with sprites. This implies a mechanism at work that causes the sprite-generated ionisation enhancements in the lower ionosphere to build up slowly, starting with the sprite onset and lasting up to about few seconds. The process is not understood and awaits further studies, both theoretical and experimental. 
The one-to-one correlation of sprite occurrences and VLF transmitter path perturbations suggests a technique to derive enhancements of electron densities in spritesand their growth- and decay rates. Alternative measurements of plasma densities could be provided by radars, but these are relatively more complicated and with limited area coverage. The VLF technique is well proven in connection with diagnostics of other phenomena in the lower ionosphere and will be a powerful tool for sprite investigations once the sprite signature is clearly identified.

Are relativistic electrons accelerated in connection with sprites? There is by now ample evidence for the presence of run-away electrons in lightning, within thunderstorms, and above the atmosphere above thunderstorm regions. The evidence is in the form of observations of $\mathbf{X}$ - and $\gamma$-ray emissions, assumed to be bremsstrahlung from relativistic electrons. However, our understanding at this point indicates that the process primarily is important for the very strongest events, which is somewhat contradictory to the predictions that the run-away discharge process has a factor $\sim 10$ lower threshold electric field than the conventional discharge. Better observations are needed and are also planned as from the French microsatellite TARANIS and the ASIM payload on the International Space Station, both scheduled for 2008 .

\section{Acknowledgements}

The EuroSprite2003 campaign was conducted as part of the Research Training Network "Coupling of Atmospheric Layers", CAL, sponsored by the EU 5. Framework Programme under contract no.: HPRN-CT-200200216. We thank Stéphane Pédeboy of the Météorage Company for providing near-real time data on lightning activity and Jean-Yves Lojou of the Vaisala group for the SAFIR data. G. Sátori's and J. Bór's contribution was supported by Grants T034309 and TS 408048 from the Hungarian Science Foundation. Support for the establishment of the Crete VLF station was provided in part by the STAR Laboratory, Stanford University, the European Office of Aerospace Research and Development (EOARD), and the Air Force Research Laboratory, under contract FA8655-03-1-3028. We thank Troy Wood of STAR Laboratory for his excellent work in installing the Crete VLF system. Stanford participation in this work is supported by the National Science Foundation and Office of Naval Research under grants ATM-9910532002 and N00014-03-1-0333.

\section{References}

Allin, T.H., Jorgensen, J.L., Neubert, T., Laursen, S., 2004. The Spritewatch - a Semi-automatic, remote controlled observa- tion system for transient luminous events. IEEE Transactions, submitted for publication.

Blanc, E., Farges, T., Roche, R., Brebion, D., Hua, T., Labarthe, A., Melnikov, V., 2004. Nadir observations of sprites from the International Space Station. Journal of Geophysical Research 109, A02306.

Burke, C.P., Jones, D.L.I., 1996. On the polarity and continuing currents in usually large lightning flashes deduced from ELF events. Journal of Atmospheric and Terrestrial Physics 58, 531-540.

Cho, M., Rycroft, M.J., 2001. Non-uniform ionisation of the upper atmosphere due to the electromagnetic pulse from a horizontal lightning discharge. Journal of Atmospheric and Solar-Terrestrial Physics 63, 559.

Collier, A.B., Hughes, A.R.W., 2002. Digital VLF recording and analysis system for Sanae IV. South African Journal of Science 98, 547-550.

Cummer, S.A., Inan, U.S., Bell, T.F., Barrington-Leigh, C.P., 1998. ELF radiation produced by electrical currents in sprites. Geophysical Research Letters 25, 1281-1284.

Dowden, R.L., Brundell, J.B., Lyons, W.A., 1996. Are VLF rapid onsets, rapid decay perturbations produced by scattering off sprite plasmas? Journal of Geophysical Research 101 (D14), 19175.

Farges, T., Blanc, E., Le Pichon, A., Neubert, T., Allin, T., 2005. Identification of infrasound produced by sprites during the Sprite2003 campaign. Geophysical Research Letters 32, L01813, doi:10.1029/2004GL021212.

Frantz, R.C., Nemzek, R.J., Winckler, J.R., 1990. Television image of a large upward electrical discharge above a thunderstorm system. Science 249, 48-51.

Friedel, R.H.W., Hughes, A.R.W., Dowden, R.L., Adam, C.D., 1993. First observations of trimpi events at Durban ( $L=1.69$ ) using an OMSKI receiver. Journal of Geophysical Research 98 (A2), 1571-1580.

Gerken, E., Inan, U., Barrington-Leigh, C., 2000. Telescopic imaging of sprites. Geophysical Research Letters 27, 2637-2640.

Haldoupis, C., Neubert, T., Inan, U., Mika, A., Allin, T.H., Marshall, R.A., 2004. Sub-ionospheric early VLF signal perturbations observed in one-to-one association with sprites. Journal of Geophysical Research 109, (A10), A10303, doi:10.1029/2004JA010651.

Hedin, A.E., Biondi, M.A., Burnside, R.G., Hernandez, G., Johnson, R.M., Killeen, T.L., Mazaudier, C., Meriwether, J.W., Salah, J.E., Sica, R.J., Smith, R.W., Spencer, N.W., Wickwar, V.B., Virdi, T.S., 1996. Revised global model of upper thermospheric winds using satellite and ground-based observations. Journal of Geophysical Research 96, $7657-7688$.

Hu, W., Cummer, S.A., Lyons, W.A., Nelson, T.E., 2002. Lightning charge moment changes for the initiation of sprites. Geophysical Research Letters 29 (8), 1279.

Huang, E., Williams, E., Boldy, R., Heckman, S., Lyons, W., Taylor, M., Nelson, T., Wong, C., 1999. Criteria for sprites and elves based on Schumann resonance observations. Journal of Geophysical Research 104 (D14), 16943-16964.

Israelevich, P.L., Yair, Y., Devir, A.D., Joseph, J.H., Levin, Z., Mayo, I., Moalem, M., Price, C., Ziv, B., Sternleib, A., 2004. Transient airglow enhancements observed from the 
space shuttle Colombia during the MEIDEX sprite campaign. Geophysical Research Letters 31, L06124.

Johnson, M.P., Inan, U.S., Lev-Tov, S.J., 1999. Scattering pattern of lightning-induced ionospheric disturbances associated with sprites. Geophysical Research Letters 26, 12363.

Jones, D.L.I., 1967. Schumann resonances and e.l.f. propagation for inhomogeneous, isotropic ionosphere profiles. Journal of Atmospheric and Terrestrial Physics 29, 1037-1044.

Jones, D.L.I., Kemp, D.T., 1970. Experimental and theoretical observations of Schumann resonances. Journal of Atmospheric and Terrestrial Physics 32, 1095-1108.

Le Pichon, A., Garcés, M.A., Blanc, E., Barthelemy, M., Drob, D.P., 2002. Acoustic propagation and atmosphere characteristics derived from infrasonic waves generated by the Concorde. Journal of the Acoustical Society of America $111,629-641$.

Lehtinen, N.G., Bell, T.F., Inan, U.S., 1999. Monte Carlo simulation of runaway $\mathrm{MeV}$ electron breakdown with application to red sprites and terrestrial gamma ray flashes. Journal of Geophysical Research 104, 24699.

Lehtinen, N.G., Inan, U.S., Bell, T.F., 2001. Effects of thunderstorm-driven runaway electrons in the conjugate hemisphere: purple sprites, ionization enhancements and gamma rays. Journal of Geophysical Research 106, 28841.

Liszka, L.J., 2004. The Possible Infrasound Generation by Sprites, Low Frequency Noise, Vibration and Active Control, in press.

Lyons, W.A., 1996. Sprite observations above the U.S. High Plains in relation to their parent thunderstorm systems. Journal of Geophysical Research 101, 29641-29652.

Lyons, W.A., Nelson, T.E., Williams, E.R., Cummer, S.A., Stanley, M.A., 2003. Characteristics of sprite-producing positive cloud-to-ground lightning during the 19 July 2000 STEPS mesoscale convective systems. Monthly Weather Review 131 (10), 2417-2427.

Marshall, R.A., Inan, U.S., Neubert, T., Hughes, A., Satori, G., Bor, J., Collier, A., Allin, T.H., 2004. Optical observations geomagnetically conjugate to sprite-producing lightning discharges. Annalesde Geophysique, submitted for publication.

Mende, S.B., Frey, H.U., Rairden, R.L., Su, H.-T., Hsu, R.-R., Allin, T.H., Neubert, T., Gerken, E.A., Inan, U.S., 2002. Fine structure of sprites and proposed global observations. In: Liu, L.H. (Ed.), Space Weather Study Using Multioint Techniques, Cospar Colloguia Series, vol. 12, Pergamon, Elsevier Science, Amsterdam, pp. 275-282.

Neubert, T., 2003. On sprites and their exotic kin. Science 300 (2), 747.

Neubert, T., Allin, T.H., Stebaek-Nielsen, H., Blanc, E., 2001. Sprites over Europe. Geophysical Research Letters 28, 3585.

Roger, C.J., Cho, M., Clilverd, M.A., Rycroft, M.J., 2001. Lower ionospheric modification by lightning-EMP: simulation of the night ionosphere over the United States. Geophysical Research Letters 28 (2), 199.

Roussell-Dupre, R.A., Gurevich, A.V., 1996. On runaway break-down and upward propagating discharges. Journal of Geophysical Research 101, 2297.
São Sabbas, F.T., Sentman, D.D., Wescott, E.M., Pinto Jr., O., Mendes Jr., O., Taylor, M.J., 2003. Statistical analysis of space-time relationships between sprites and lightning. Journal of Atmospheric and Solar-Terrestrial Physics 65, 525 .

Schumann, W.O., 1952. On the free oscillations of a conducting sphere which is surrounded by an air layer and an ionosphere shell. Zeitschriftfuer Naturforschaftung 7a, $149-154$.

Sentman, D.D., Wescott, E.M., Picard, R.H., Winick, J.R., Stenbaek-Nielsen, H.C., Dewan, E.M., Moudry, D.R., São Sabbas, F.T., Heavner, M.J., Morill, J., 2003. Simultaneous observations of mesospheric gravity waves and sprites generated by a midwestern thunderstorm. Journal of Atmospheric and Solar-Terrestrial Physics 65, $537-550$.

Snively, J.B., Pasko, V.P., 2003. Breaking of thunderstormgenerated gravity waves as a source of short-period ducted waves at mesopause altitudes. Geophysical Research Letters 30 (24), 2254.

Stanley, M., Krehbiel, P., Brook, M., More, C., Rison, W., Abrahams, B., 1999. High speed video of initial sprite development. Geophysical Research Letters 26, 3201.

Stenbaek-Nielsen, H.C., Moudry, D.R., Wescott, E.M., Sentman, D.D., Sâo, F.T., 2000. Sprites and possible mesospheric effects. Journal of Geophysical Research 27, 3829.

Symbalisty, E.M.D., Roussel-Dupre, R.A., ReVelle, D.O., Suszcynsky, D.M., Yukhimuk, V.A., Taylor, M.J., 2000. Meteor trails and columniform sprites. Icarus 148 (1), 65-79.

Valdivia, J.A., Milikh, G.M., Papadopoulos, K., 1998. Model of red sprites due to intracloud fractal lightning discharges. Radio Science 33, 1655.

Virieux, J., Garnier, N., Blanc, E., Dexa, J.X., 2004. Paraxial ray tracing for atmospheric wave propagation. Geophysical Research Letters, accepted for publication.

Vivas Veloso, J.A., Christie, D.R., Campus, P., Bell, M., Hoffmann, T.L., Langlois, A., Martysevich, P., Demirovik, E., Carvalho, J., Kramer, A., 2002. Status report on the establishment of the Comprehensive Nuclear-Test-Ban Treaty (CTBT) International Monitoring System (IMS) infrasound network. Journal of the Acoustical Society of America 112 (5), 2352.

Wait, J.R., 1962. Electromagnetic Waves in Stratified Media, second ed. Pergamon Press, New York, 1962, p. 153, Section 5.

Yair, Y., Price, C., Levin, Z., Joseph, J., Israelevitch, P., Devir, A., Moalem, M., Ziv, B., Asfur, M., 2003. Sprite observations from the space shuttle during the Mediterranean Israeli Dust Experiment (MEIDEX). Journal of Atmospheric and Solar-Terrestrial Physics 65, 635-642.

Yair, Y., Israelevich, P., Devir, A., Moalem, M., Price, C., Joseph, J.H., Levin, Z., Ziv, B., Sternleib, A., Teller, A., 2004. New observations of sprites from the space shuttle. Journal of Geophysical Research 109, D15201.

Zabotin, N.A., Wright, J.W., 2001. Role of meteoric dust in sprite formation. Geophysical Research Letters 28 (13), 2593. 